\title{
Intestinal Bleeding Associated with Antiphospholipid Antibody Syndrome
}

Antiphospholipid antibody syndrome is characterized by recurrent vascular thromboses or recurrent complications of pregnancy, including miscarriage or premature birth [1-3]. Thrombosis caused by autoantibodies directed against phospholipid-binding proteins can occur in any tissue. We present the case of a patient with antiphospholipid antibody syndrome and intestinal bleeding.

A 73-year-old woman who was known to have antiphospholipid antibody syndrome was hospitalized in the dermatology department at our medical center, because of leg ulcers. When she developed hematochezia, she was referred to our surgical service. The source of bleeding was found to be an ulcer in the transverse colon (Figure $\mathbf{1}$ ), that was not actively bleeding at the time of the examination. Biopsies were taken and histological examination showed morphological changes compatible with antiphospholipid antibody syndrome (Figure 2 ). The degree of blood loss was reflected in a hematocrit of $25 \%$, hemoglobin concentration of $7.4 \mathrm{~g} / \mathrm{dl}$, and erythrocyte count of $3.13 \times 10^{12} / 1$. The beta-2-glycoprotein-1 antibody screen and cardiolipin antibody screen were positive. Cortisone was administered and then tapered off. There were no further episodes of intestinal bleeding and colonoscopy 1 week later showed that the ulcer had healed.

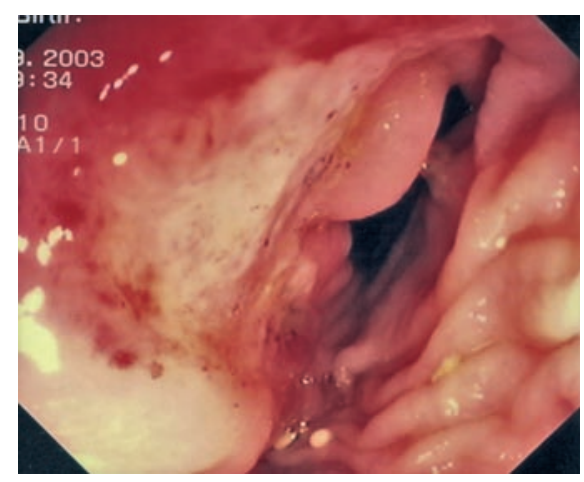

Figure 1 Endoscopic view, showing an ulcer in the transverse colon.

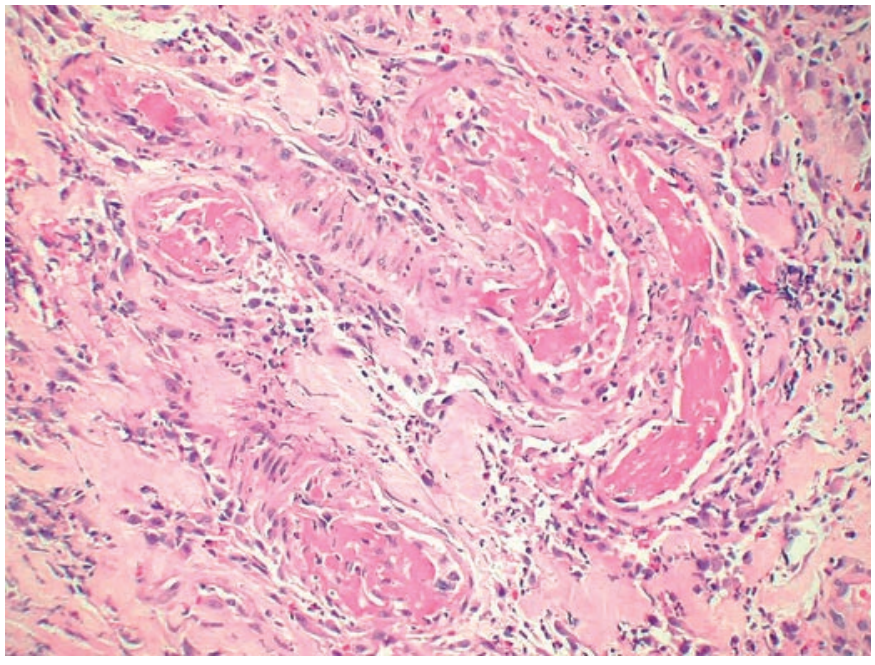

Figure 2 Histological view of a biopsy specimen, showing small venules with intraluminal fibrin thrombi.

The thrombotic manifestations of antiphospholipid syndrome can affect the vessels of any organ: 55\% of patients have venous thrombosis, particularly of the lower limb, and half that $55 \%$ of them have pulmonary emboli [4]. Arterial thrombosis involves the brain in $50 \%$ of patients, causing transient ischemic attacks or strokes; in $25 \%$ arterial thrombosis of the heart causes coronary occlusion; and the eye, kidney or peripheral arteries are involved in $25 \%$ of patients [4].

Gastrointestinal bleeding has been described in only a few cases, caused by mesenteric thrombosis and small-bowel ischemia, with ulcer of the descending duodenum [5]. To our knowledge, there is no previous record of a patient with a bleeding colonic ulcer.

The mainstay of therapy is full anticoagulation. Lifelong anticoagulation is indicated after a single thrombotic event.

\section{P. Kornprat ${ }^{1}$, H. Bacher ${ }^{1}$, H. Cerwenka ${ }^{1}$,}

A. El-Shabrawi ${ }^{1}$, C. Langner ${ }^{2}$,

\section{H.-J. Mischinger ${ }^{1}$}

1 Division of General Surgery, Department of Surgery, University Medical Center, Graz, Austria

2 Department of Pathology, University Medical Center, Graz, Austria.
References

${ }^{1}$ Cucurull E, Gharavi AE, Menon Yet al. Antiphospholipid antibody syndrome. Vasc Dis 2003; 5: 127-136

${ }^{2}$ Cines DB, McCrae KR. The antiphospholipid-protein syndrome. J Clin Immunol 1995; 15: 86S-100S

${ }^{3}$ Nahass GT. Antiphospholipid antibodies and the antiphospholipid antibody syndrome. J Am Acad Dermatol 1997; 36: 149- 168

${ }^{4}$ Alarcon-Segovia D, Perez-Vazquez ME, Villa ARet al. Preliminary classification criteria for the antiphospholipid syndrome within systemic lupus erythematosus. Semin Arthritis Rheum 1992; 21: $275-286$

${ }^{5}$ Cappell MS, Mikhail N, Gujral N. Gastrointestinal hemorrhage and intestinal ischemia associated with anticardiolipin antibodies. Dig Dis Sci 1994; 39: 1359-1364

\section{Corresponding Author}

\section{P. Kornprat}

Division of General Surgery, Department of Surgery, University Medical Center

Auenbruggerplatz 29

8036 Graz

Austria

Fax: $\quad+43-316-3854666$

E-mail: peter.kornprat@meduni-graz.at 